\title{
Variation in Lipid Compositions during the Ovarian Maturation of the Prawn
}

\author{
Shin-ichi Teshima* and Akio Kanazawa* \\ (Accepted October 4, 1982)
}

\begin{abstract}
This paper presents the variation in lipid compositions during the ovarian maturation of the prawn Penaeus japonicus. The ovarian lipid concentrations increased during the slight mature and yellow ovarian periods, remained at roughly constant levels during the subsequent ovarian period to spawning, and then decreased to low levels at the spent ovaries. The hepatopancreatic lipid concentrations increased with increasing maturity of the ovaries, reached a maximum level at the yellow period of ovaries, and then decreased during the subsequent period to spawning. These results suggest the possible movement of hepatopancreatic lipids to the ovaries during the ovarian maturation. Both triglycerides and phospholipids were responsible for the increase in ovarian lipid concentrations during the sexual maturation. The fatty acid composition of lipids, triglycerides, and phospholipids of the ovaries did not vary markedly during the ovarian maturation.
\end{abstract}

The control of ovarian maturation in indoor tanks is one of the unresolved problems in the complete culture from hatching to spawning of the prawn Penaeus japanicus in Japan. Although KANAZAWA $^{1)}$ and several groups of workers ${ }^{23}$ have succeeded in obtaining the spawning mother $P$. japonicus by controlling water temperature and/or photo-period after removal of one of the eyestalks, the mechanism by which the prawn matures sexually and spawns is still obscure.

On the other hand, lipids are important nutrients for growth of crustaceans not only as energy sources but also as essential nutrients such as sterols, ${ }^{8)}$ essential fatty acids, ${ }^{4)}$ and phospholipids. ${ }^{0)}$ In crustaceans, the hepatopancreas is generally regarded as a major lipid storage organ analogous to the fat body in insects and the adipose tissue and liver in vertebrates. ${ }^{\theta)}$ The stored lipids are transported to some orangs and tissues during a certain period such as the premolt stage. ${ }^{7)}$ In the case of female crustaceans, the ovaries are also shown to contain higher levels of lipids than other organs, ${ }^{8-10)}$ and this suggests that lipids are important substances for maturation of crustacean ovaries. However, only a little information is available for lipid metabolism relating to the ovarian maturation of crustaceans. As part of investigating the lipid metabolism during the ovarian maturation of $P$. japonicus, the authors intend to clarify the variation in lipid compositions of the ovary, hepatopancreas, hemolymph, and muscle during the development of ovaries.

\section{Materials and Methods}

The specimens of female prawn $P$. japonicus were caught by fishermen in the sea near Miyazaki, Japan, on June 5 and September 15, and transported to this laboratory. The alive prawns were dissected for lipid analysis, and some prawns were held in a tank (500l) until spawned in order to choose the individuals with the spent ovaries. Ovarian development was arbitrarily grouped into the following 5 stages with gonadosomatic index (GSI = ovary wt. $\times 100 /$ body wt.); stage I (GSI $<$ 2.0, immature ovaries), stage II (GSI 2.0-4.9, slightly mature ovaries), stage III (GSI 5.0-8.0, ovaries at yellow period), stage IV (GSI $>8.0$, well-mature ovaries), and stage V (spent ovaries). The stages adopted in this study almost correspond to those which were described for $P$. japonicus, ${ }^{11}$ Penaeus setiferus, ${ }^{12}$ and Penaeus merguiensi ${ }^{13}{ }^{13}$ on the basis of external examination of alive specimens.

Lipids were extracted with chloroformmethanol-water $\left.(2: 2: 1)^{14}\right)$ from the ovary, hepatopancreas, hemolymph, and muscle of $P$. japonicus. Lipid concentrations ( $\%$ of wet weight) were determined gravimetrically for the ovary hepatopancreas, and muscle, and photometrically ${ }^{15)}$ for

* Faculty of Fisheries, University of Kagoshima, 50-20 Shimoarata-4, Kagoshima 890, Japan (手島新一 - 金沢昭夫：鹿児島大学水学部) 
the hemolymph. Lipids were separated into lipid classes such as hydrocarbons (HC), steryl esters (SE), triglycerides (TG), free fatty acids (FFA), diglycerides (GD), free sterols (FS, mostly cholesterol), monoglycerides (MG), and phospholipids (PL) by thin layer chromatography on Kieselgel $G$ using the solvent systems ${ }^{16)}$ : 1st, isopropyl ether-acetic acid $(96: 4) ; 2 \mathrm{nd}$, petroleum ether-ether-acetic acid (90:10:1). Each lipid class was quantified by the method of AMENTA. ${ }^{15}$ ) Fatty acid compositions were determined by gasliquid chromatography on $10 \%$ DEGS and $5 \%$ Shinchrom E-71 as described previously. ${ }^{17}$ )

Statistical analysis of data on lipid concentrations was conducted by an analysis of variance at the $1 \%$ or $5 \%$ level.

\section{Results and Disscusion}

In this study, the lipid compositions of the ovary, hepatopancreas, hemolymph, and muscle were investigated with the early (June samples) and late (September samples) matured groups of female $P$. japonicus with the various degrees of ovarian maturity.

Fig. 1 and Table 1 show the variation in lipid concentrations of the ovary, hepatopancreas, hemolymph, and muscle in the prawns collected on June 5. The lipid concentrations of the muscle and hemolymph were lower than those of the ovary and hepatopancreas, and they did not change markedly during the ovarian development. Whereas, the lipid concentrations of the ovary and hepatopancreas varied with the degree of ovarian maturity. The ovarian lipid concentrations increased during the slightly mature and yellow periods (GSI 2.6 to about 7), remained

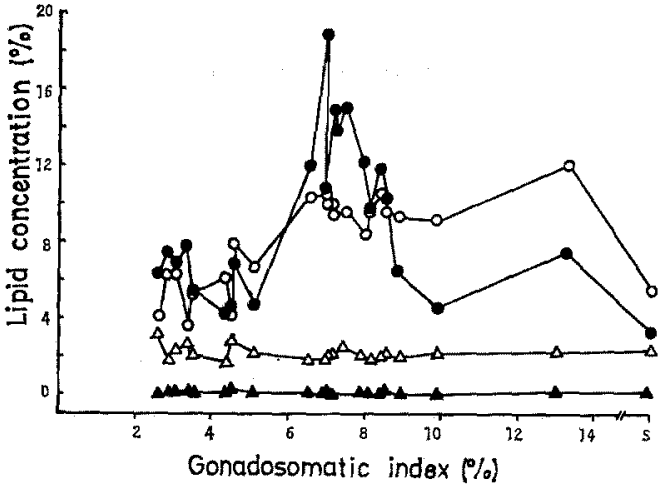

Fig. 1. Variation in lipid concentrations $(\%$ of wet weight) of the ovary, hepatopancreas, hemolymph, and muscle during the ovarian maturation of $P$. japonicus. $O$, ovary; $\boldsymbol{O}$, hepatopancreas; $\boldsymbol{\Lambda}$, hemolymph; $\triangle$, muscle. $S$ indicates the spent ovaries.

relatively constant levels during the subsequent period until spawning, and decreased to low levels after spawning (Fig. 1). The statistical analysis showed that the average concentrations of ovarian lipids on the June samples were significantly different between the following ovarian stages: stages II-III $(\mathrm{P}<0.01)$, III-IV $(\mathrm{P}<0.05)$, and IV-V $(P<0.01)$ (Table 1). The lipid concentration of slightly mature ovaries (stage II) was not significantly $(P<0.01)$ different with that of spent ovaries (stage $\mathrm{V}$ ). The amounts of ovarian lipids per one prawn increased remarkably with increasing GSI values from about $50 \mathrm{mg}$ to $1300 \mathrm{mg}$ (Fig. 2). This implies that large quantities of lipids were necessary for development of ovaries.

The hepatopancreatic lipid concentrations of the June samples increased with increasing GSI

Table 1. Variation in lipid concentrations of the ovary, hepatopancreas, hemolymph, and muscle during the ovarian maturation of $P$. japonicus

\begin{tabular}{cccccccc}
\hline \multirow{2}{*}{$\begin{array}{c}\text { Sampling } \\
\text { date }\end{array}$} & $\begin{array}{c}\text { Ovarian } \\
\text { stage }\end{array}$ & $\begin{array}{c}\text { Body wt. } \\
(\mathrm{g})\end{array}$ & GSI $(\%)^{* 1}$ & \multicolumn{4}{c}{ Lipid concentration (\% of wet wt.) } \\
\cline { 6 - 8 } & & & & Ovary & Hepatopancreas & Hemolymph & Muscle \\
\hline \multirow{3}{*}{ June } & II & $47.1-109.1$ & $2.9-4.9$ & $5.45 \pm 1.43(8)^{* 2}$ & $6.21 \pm 1.35(8)$ & $0.62 \pm 0.20(8)$ & $2.26 \pm 0.56(8)$ \\
& II & $52.4-68.0$ & $5.0-8.0$ & $9.29 \pm 1.30(8)$ & $12.70 \pm 2.90(8)$ & $0.43 \pm 0.09(8)$ & $2.14 \pm 0.24(8)$ \\
& IV & $60.0-160.0$ & 8.0 & $10.09 \pm 1.42(6)$ & $8.57 \pm 2.09(6)$ & $0.42 \pm 0.07(6)$ & $2.01 \pm 0.31(6)$ \\
& V & $94.6-98.9$ & - & $5.56 \pm 1.40(3)$ & $3.40 \pm 1.00(3)$ & $0.35 \pm 0.06(3)$ & $2.38 \pm 0.43(3)$ \\
Septem- & II & $41.1-48.4$ & $4.0-4.9$ & $5.99 \pm 1.11(5)$ & $5.97 \pm 1.20(5)$ & $0.41 \pm 0.05(5)$ & $2.47 \pm 0.60(5)$ \\
ber 15 & III & $37.6-103.5$ & $5.0-8.0$ & $8.46 \pm 1.23(6)$ & $13.72 \pm 2.40(6)$ & $0.43 \pm 0.01(6)$ & $2.42 \pm 0.56(6)$ \\
& IV & $114.5-141.0$ & 8.0 & $10.12 \pm 1.60(4)$ & $8.01 \pm 1.97(4)$ & $0.45 \pm 0.05(4)$ & $2.28 \pm 0.22(4)$ \\
& V & $71.8-110.1$ & - & $6.05 \pm 1.10(5)$ & $6.65 \pm 1.54(5)$ & $0.39 \pm 0.01(5)$ & $2.05 \pm 0.43(5)$ \\
\hline
\end{tabular}

*1. Gonadosomatic index $=$ (Ovary wt. $\times 100$ )/Body wt.

*2 S.D. and the number of prawns analysed. 


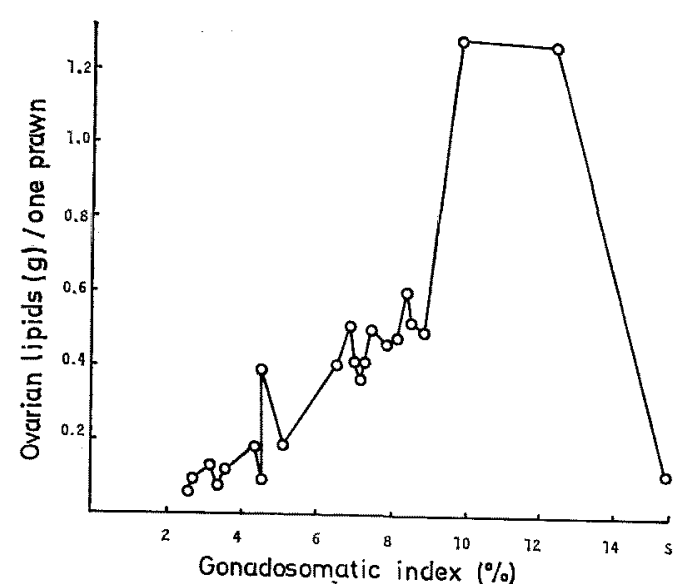

Fig. 2. Variation in the quantity of ovarian lipids

(g) per one prawn during the ovarian maturation of $\boldsymbol{P}$. japonicus. $\mathrm{S}$ indicates the spent ovaries.

values, reached the highest level at the yellow period (GSI 6.5-7.5), and then decreased until spawning (Fig. 1). The average concentrations of hepatopancreatic lipids were significantly $(P<0.01)$ different between the following stages: stages II-III, III-IV, and IV-V (Table 1). As for the crab Parathelphusa hydrodromus, ADIYODI and $A D I Y O I^{18)}$ have also observed an increase in the ovarian lipid concentration at the end of the first phase (stages 2-3) of vitellogenesis and a decrease in the hepatopancreatic lipids during the same stages.

As for the September samples of female prawns, the similar results to those with the June samples were obtained about the lipid concentrations of the ovary, hepatopancreas, hemolymph, and muscle (Table 1). The highest values for the ovarian and hepatopancreatic lipid concentrations again appeared at stages IV and III, respectively. These results suggest that there is no essential difference between the early and late matured prawns about the lipid metabolism relating to the maturation of ovaries. Tables 2 and 3 show the variation in the fatty acid composition of lipids extracted from the ovary, hepatopancreas, hemolymph, and muscle during the ovarian maturation. The ovarian lipids contained higher proportions of $20: 5 \omega 3$ and $22: 6 \omega 3$ than the hepatopancreas in every stage of ovarian maturation. Literatures have shown that the ovaries of $P$. japonicus $^{10}$ ) and the crab Cancer magister ${ }^{18)}$ contained more palmitic acid (16:0) and particularly monoenoic acids such as palmitoleic (16:1) and oleic $(18: 1)$ acids than the other organs. The results of the present study showed that the ovarian lipids did not contain markedly higher proportions of $16: 0$ and $18: 1$ than the lipids of hepatopancreas, hemolymph, and muscle, although the proportions of 16:1 were higher in the lipids of ovary and hepatopancreas than in the lipids of hemolymph and muscle throughout the process of ovarian development. No remarkable variation in the fatty acid composition was not seen about the lipids of ovary and hepatopancreas during the ovarian maturation, except for a slight increase in the proportio of $22: 6 \omega 3$ in the hepatopancreatic lipids at stages IV and V. The fatty acid compositions of both hemolymph and muscle also remained roughly constant during the ovarian development.

Concerning the September samples, the lipids of the ovary, hepatopancreas, hemolymph, and muscle were separated into lipid classes to clarify

Table 2. Variation in fatty acid compositions $(\%)$ of total lipids of the ovary and hepatopancreas during the ovarian maturation in the prawns collected on September 15

\begin{tabular}{|c|c|c|c|c|c|c|c|c|}
\hline \multirow{3}{*}{$\begin{array}{l}\text { Main } \\
\text { fatty } \\
\text { acid }\end{array}$} & \multicolumn{4}{|c|}{ Ovary } & \multicolumn{4}{|c|}{ Hepatopancreas } \\
\hline & \multicolumn{4}{|c|}{ Ovarian maturity } & \multicolumn{4}{|c|}{ Ovarian maturity } \\
\hline & II & III & IV & V & II & III & IV & $\mathrm{V}$ \\
\hline $14: 0$ & 39 & 3.4 & 3.4 & 2.5 & 6.0 & 4.7 & 3.4 & 3.7 \\
\hline $16: 0$ & 22.7 & 23.0 & 23.0 & 22.3 & 25.0 & 26.1 & 24.3 & 23.3 \\
\hline $16: 1$ & 17.0 & 20.6 & 20.0 & 18.6 & 16.5 & 19.5 & 19.1 & 17.4 \\
\hline $18: 0$ & 6.2 & 6.1 & 5.3 & 5.3 & 6.3 & 6.8 & 5.7 & 6.2 \\
\hline $18: 1 \omega 9$ & 21.9 & 20.0 & 21.1 & 21.1 & 16.7 & 15.9 & 20.0 & 18.7 \\
\hline $18: 2 \omega 6$ & 0.3 & 0.1 & 0.1 & 0.1 & 0.1 & 0.1 & 0.1 & 0.1 \\
\hline $18: 3 \omega 3$ & 0.4 & 0.4 & 0.6 & 0.6 & 0.5 & 0.8 & 0.5 & 1.0 \\
\hline $20: 1 \omega 9$ & 4.5 & 3.7 & 3.4 & 2.7 & 9.9 & 7.2 & 5.0 & 6.5 \\
\hline $20: 4 \omega 6$ & 3.6 & 3.3 & 3.6 & 4.4 & 3.4 & 3.6 & 3.6 & 4.5 \\
\hline $20: 5 \omega 3$ & 5.5 & 5.8 & 5.9 & 7.2 & 3.5 & 2.9 & 4.0 & 3.8 \\
\hline $22: 6 \omega 3$ & 5.0 & 6.4 & 7.1 & 5.4 & 2.5 & 1.9 & 5.4 & 4.6 \\
\hline
\end{tabular}


Table 3. Variation in fatty acid compositions (\%) of total lipids of the hemolymph and muscle during the ovarian maturation in the prawns collected on September 15

\begin{tabular}{|c|c|c|c|c|c|c|c|c|}
\hline \multirow{3}{*}{$\begin{array}{l}\text { Main } \\
\text { fatty } \\
\text { acid }\end{array}$} & \multicolumn{4}{|c|}{ Hemolymph } & \multicolumn{4}{|c|}{ Muscle } \\
\hline & \multicolumn{4}{|c|}{ Ovarian maturity } & \multicolumn{4}{|c|}{ Ovarian maturity } \\
\hline & II & III & IV & $\mathbf{V}$ & II & III & IV & V \\
\hline $14: 0$ & 4.2 & 2.4 & 2.4 & 2.5 & 1.7 & 1.4 & 1.6 & 1.4 \\
\hline $16: 0$ & 21.4 & 18.8 & 21.9 & 19.6 & 21.1 & 19.2 & 19.5 & 21.9 \\
\hline $16: 1$ & 10.4 & 14.2 & 14.7 & 12.9 & 13.9 & 15.3 & 14.1 & 14.4 \\
\hline $18: 0$ & 10.6 & 10.4 & 9.8 & 8.9 & 10.3 & 9.3 & 10.8 & 11.1 \\
\hline $18: 1 \omega 9$ & 18.4 & 19.8 & 21.2 & 20.6 & 19.9 & 20.5 & 21.2 & 18.5 \\
\hline $18: 2 \omega 6$ & 1.0 & 1.2 & 0.8 & 0.8 & 0.5 & 0.5 & 0.5 & 0.5 \\
\hline $18: 3 \omega 3$ & 0.3 & 0.4 & 0.4 & 0.5 & 0.2 & 0.2 & 0.1 & 0.5 \\
\hline $20: 1 \omega 9$ & 4.1 & 3.5 & 2.8 & 2.8 & 2.6 & 2.2 & 1.7 & 1.8 \\
\hline $20: 4 \omega 6$ & 5.1 & 5.3 & 3.8 & 7.3 & 4.4 & 4.9 & 4.8 & 4.2 \\
\hline $20: 5 \omega 3$ & 8.7 & 5.4 & 4.8 & 6.0 & 7.5 & 9.2 & 8.1 & 8.2 \\
\hline $22: 6 \omega 3$ & 5.3 & 5.6 & 7.7 & 4.2 & 7.0 & 7.9 & 7.0 & 7.7 \\
\hline
\end{tabular}

Table 4. Variation in lipid class compositions during the ovarian maturation of prawns collected on September 15

\begin{tabular}{|c|c|c|c|c|c|}
\hline \multirow{2}{*}{ Organ or tissue } & \multirow{2}{*}{ Lipid class*1 } & \multicolumn{4}{|c|}{ Composition ( $\%$ of total lipids) } \\
\hline & & Stage II & Stage III & Stage IV & Stage V \\
\hline \multirow{8}{*}{ Ovary } & PL & 39.0 & 46.3 & 46.4 & 60.8 \\
\hline & MG & $\mathrm{t}^{* 2}$ & 0.9 & 1.1 & $\mathbf{t}$ \\
\hline & FS & 4.0 & 5.9 & 5.1 & 6.1 \\
\hline & $\mathrm{DG}$ & 2.3 & 3.9 & 1.6 & 1.5 \\
\hline & FFA & 20.7 & 11.0 & 14.6 & 6.4 \\
\hline & TG & 24.2 & 27.9 & 27.9 & 21.0 \\
\hline & SE & 2.8 & 1.9 & 1.3 & 1.2 \\
\hline & $\mathrm{HC}$ & 7.0 & 2.2 & 2.0 & 3.0 \\
\hline \multirow{8}{*}{ Hepatopancreas } & PL & 24.6 & 19.4 & 28.0 & 33.9 \\
\hline & MG & 0.4 & 2.1 & 1.7 & t \\
\hline & FS & 5.1 & 7.5 & 6.1 & 3.1 \\
\hline & $\mathrm{DG}$ & 5.8 & 5.6 & 4.2 & 2.2 \\
\hline & FFA & 19.0 & 13.9 & 11.0 & 10.0 \\
\hline & $\mathrm{TG}$ & 29.2 & 34.7 & 34.7 & 35.8 \\
\hline & SE & 4.4 & 5.7 & 4.7 & 5.6 \\
\hline & $\mathrm{HC}$ & 11.5 & 11.1 & 9.6 & 9.4 \\
\hline \multirow{8}{*}{ Hemolymph } & PL & 31.7 & 39.5 & 51.0 & 60.0 \\
\hline & MG & $\mathrm{t}$ & 1.1 & $t$ & $t$ \\
\hline & FS & 9.9 & 7.1 & 9.5 & 7.1 \\
\hline & $\mathrm{DG}$ & 7.2 & 5.4 & 7.0 & 5.3 \\
\hline & FFA & 7.2 & 6.1 & 5.8 & 4.6 \\
\hline & $\mathrm{TG}$ & 34.0 & 26.5 & 16.5 & 14.3 \\
\hline & SE & 5.0 & 6.5 & 5.2 & 4.8 \\
\hline & $\mathrm{HC}$ & 5.0 & 7.8 & 5.0 & 3.9 \\
\hline \multirow{8}{*}{ Muscle } & PL & 60.7 & 68.3 & 68.7 & 53.9 \\
\hline & MG & $t$ & $t$ & $\mathrm{t}$ & $\mathrm{t}$ \\
\hline & FS & 14.2 & 15.0 & 15.0 & 30.2 \\
\hline & $\mathrm{DG}$ & 4.9 & 1.1 & 2.0 & 2.8 \\
\hline & FFA & 4.0 & 2.5 & 2.0 & 1.4 \\
\hline & $\mathrm{TG}$ & 7.3 & 4.8 & 5.0 & 5.0 \\
\hline & $\mathrm{SE}$ & 4.9 & 2.7 & 2.5 & 1.4 \\
\hline & $\mathrm{HC}$ & 4.0 & 5.6 & 4.8 & 5.3 \\
\hline
\end{tabular}

*1 PL, phospholipids; MG, monoglycerides; FS, free sterols; DG, diglycerides; FFA, free fatty acids; TG, triglycerides; SE, steryl esters; HC, hydrocarbons.

*2 Less than $0.1 \%$ 

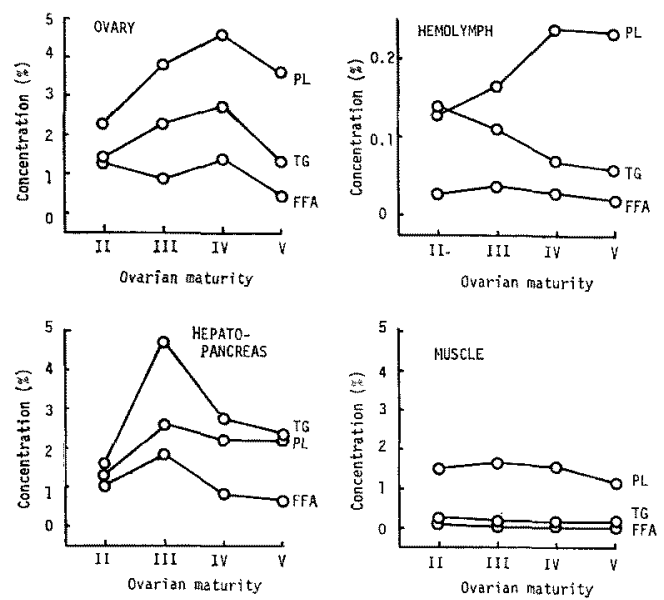

Fig. 3. Variation in the concentrations of major lipid classes of the ovary, hepatopancreas, hemolymph, and muscle during the ovarian maturation of $P$. japonicus.

the variation in qualities of lipids. The muscle of $P$. japonicus contained high levels of PL (53.9$68.3 \%$ of total lipids) and FS $(13.0-30.2 \%)$ as pointed out in the muscles of $P$. japonicus ${ }^{10}$ ) and the queen crab Chionocetes opilio (Table 4). ${ }^{20)}$ The ovaries contained PL (31.7-60.8\%), FS $(6.4-22.0 \%)$, and TG $(21.0-27.9 \%)$ as the major lipid classes in every stage of ovarian maturation. The results apparently did not agree with those obtained by GUARY et al. ${ }^{10)}$ who showed that the ovaries of $P$. japonicus (GSI $=3.2$ ) contained large amounts of TG $(53.0 \%)$ besides cholesterol $(15.3 \%)$ and PL (12.5\%) as the major lipid classes. As shown in Table 4 and Fig. 3, the concentrations of PL and TG in the ovaries increased with the progress of ovarian maturation. Therefore, the increase in the concentration of ovarian lipids during the ovarian maturation (Fig. 1 and Table 1) are conceived to be due mainly to that in both PL and TG. However, the fatty acid compositions of ovarian PL and TG remained roughly constant throughout the developmental stages of ovaries (Table 5). These results suggest that the ovarian lipids increase quantitatively during the sexual maturation but their qualities do not vary so remarkably in the prawn $P$. japonicus.

The muscle contained PL (53.9-68.7\%) and FS $(14.2-30.2 \%)$ as the major lipid classes as reported previously by GUARY et al. ${ }^{10}$ ) The hepatopancreas contained PL (19.4-33.9\%), TG (29.2-35.8\%), and FFA $(10.0-19.0 \%)$ as the prominent lipid classes (Table 4), and the 3 lipid classes were mainly responsible for the increase in hepatopancreatic lipid concentrations during stages III-IV (Fig. 3). While, the decrease in the lipid concentration of hepatopancreas between stage IV-V was mostly attributable to that in the hepatopancreatic TG. This assumes that the hepatopancreatic TG are possibly transported to the developing ovaries during the period of stages III-IV. Interestingly, however, the hemolymph lipids were rich in PL rather than TG during the same periods. Considering these facts, we postulate that the hepatopancreatic TG may move to the ovaries as a form of lipoproteins rich in PL after being transformed to $\mathrm{PL}$ within the hepatopancreas or hemolymph. The above assumption may be supported by tracer experiments $^{21)}$ showing that lipid transport in $P$. japonicus is basically carried out as a form of high density lipoproteins containing large amounts of PL as lipid classes.

Table 5. Variation in fatty acid compositions (\%) of the ovarian phospholipids and triglycerides during the ovarian maturation in the prawns collected on September 15

\begin{tabular}{|c|c|c|c|c|c|c|c|c|}
\hline \multirow{3}{*}{$\begin{array}{l}\text { Main } \\
\text { fatty } \\
\text { acid }\end{array}$} & \multicolumn{4}{|c|}{ Phospholipids } & \multicolumn{4}{|c|}{ Triglycerides } \\
\hline & \multicolumn{4}{|c|}{ Ovarian maturity } & \multicolumn{4}{|c|}{ Ovarian maturity } \\
\hline & II & III & IV & V & II & III & IV & $\mathrm{V}$ \\
\hline $14: 0$ & 2.5 & 2.4 & 2.4 & 2.5 & 7.1 & 8.5 & 7.7 & 7.9 \\
\hline $16: 0$ & 17.4 & 18.8 & 21.9 & 19.6 & 30.5 & 32.0 & 32.4 & 29.9 \\
\hline $16: 1$ & 10.4 & 14.2 & 14.7 & 12.9 & 14.1 & 17.6 & 17.2 & 16.7 \\
\hline $18: 0$ & 10.6 & 10.4 & 9.8 & 8.9 & 4.8 & 4.4 & 3.2 & 3.4 \\
\hline $18: 1 \omega 9$ & 21.3 & 19.8 & 21.2 & 20.6 & 19.5 & 18.3 & 21.4 & 19.2 \\
\hline $18: 2 \omega 6$ & 1.0 & 1.2 & 0.8 & 0.8 & 0.7 & 0.7 & 0.6 & 0.6 \\
\hline $18: 3 \omega 3$ & 0.4 & 0.4 & 0.4 & 0.5 & 0.7 & 0.8 & 0.6 & 0.9 \\
\hline $20: 1 \omega 9$ & 4.0 & 3.5 & 2.8 & 2.9 & 4.6 & 4.2 & 3.6 & 4.1 \\
\hline $20: 4 \omega 6$ & 5.4 & 5.3 & 3.8 & 7.3 & 2.5 & 1.6 & 1.5 & 2.0 \\
\hline $20: 5 \omega 3$ & 9.7 & 6.4 & 5.8 & 8.0 & 2.7 & 1.6 & 1.1 & 2.8 \\
\hline $22: 6 \omega 3$ & 6.0 & 5.6 & 7.7 & 4.2 & 3.1 & 1.7 & 1.8 & 2.3 \\
\hline
\end{tabular}




\section{Acknowledgement}

We wish to express our thanks to Mr. H. MORIKI for his technical help during this study.

\section{References}

1) A. Kanazawa: Fish Culture, 18, 94-97 (1981).

2) A. KanAzaWA: in "Control of Ovarian Maturation and Spawning of Aquatic Animals (in Japanese)" (ed. by Japan. Soc. Sci. Fish.), Suisangaku Series No. 39, Koseisha-Koseikaku, Tokyo, 1982, pp. 80-89.

3) A. Kanazawa, N. Tanaka, S. Teshima, and K. KashLWADA: Bull. Japan. Soc. Sci. Fish., 37, 211-215 (1971).

4) S. Teshima: in "Fish Culture and Dietary Lipids (in Japanese)" (ed. by Japan. Soc. Sci. Fish.), Suisangaku Series No. 22, Koseisha-Koseikaku, Tokyo, 1978, pp. 60-77.

5) A. Kanazawa: Proc. 2nd Int. Conf. Aquacult. Nutr., in press.

6) A. K. Huggins and K.A. Munday: in "Advances in Comparative Physiology and Biochemistry" (ed. by O. LoWENSTEIN), Vol. 3, Academic Press, New York, 1968, pp. 271-378.

7) T. Ando, A. Kanazawa, S. Teshima, J. Patrois, and J. J. Ceccaldi: Bull. Japan. Soc. Sci. Fish.,
43, 1445-1449 (1977).

8) A. J. De Koning and K. B. McMullan: $J$. Sci. Food Agr., 17, 117-120 (1966).

9) R. J. Morris: J. Mar. biol. Ass. U.K., 53, 27-37 (1973).

10) J. C. Guary, M. Kayama, and Y. Murakami: Bull. Japan. Soc. Sic. Fish., 40, 1027-1032 (1974).

11) M. Hudinaga: Japan. J. Zool., 10, 305-393 (1942).

12) J. E. KING: Biol. Bull., 19, 244-262 (1948).

13) D. J. Tuma: Aust. J. Freshwater Res., 18, 73-88 (1967).

14) E. G. Bligh and W. J. Dyer: Can. J. Biochem. Physiol., 37, 911-917 (1959).

15) J. S. AMENTA: J. Lipid Res., 5, 270-272 (1964).

16) V. S. Skipsi, A. F. Smolowe, R. C. Sullvan, and M. Barclay: Biochim. Biophys. Acta, 106, 386396 (1965).

17) S. Teshima, A. Kanazawa, and H. Okamoto: Mem. Fac. Fish. Kagoshima Univ., 25, 41-46 (1976).

18) R. G. ADryodr and C. A. Adryodr: Indian J. Expl. Biol., 9, 514-515 (1971).

19) W. V. Allen: J. Fish. Res. Bd. Can., 28, 11911195 (1971).

20) R. F. Addison, R. G. ACKMAN, and J. HrNGLeY: J. Fish. Res. Bd. Can., 25, 2083-2090 (1968).

21) S. Teshima and A. Kanazwa: Min. Rev. Data File Fish. Res., Kagoshima Univ., 1, 1-25 (1980). 